Altai State University

Acta Biwlogica Sibirica

Journal of Biology

Founded in 2015 www.asu.ru

ISSN 2412-1908

Acta Biologica Sibirica, 2017, 3(4), 77-80

\title{
Primula macrocalyx Bunge (Primulaceae) in the Tyumen Province
}

\author{
O.A. Kapitonova, V.I. Kapitonov, Yu.A. Tyulkin \\ Tobolsk complex scientific station of UB RAS, 626152, Tyumen Region, Tobolsk, \\ str. named after Academician Yu. Osipov, 15, Russia \\ e-mail:kapoa.tkns@gmail.com; kvi@udsu.ru; yu.tiulkin@yandex.ru
}

\begin{abstract}
Information about the find of Primula macrocalyx Bunge in the Tyumen Province is given. On the territory of the province this species was first found by P.N. Krylov in 1937. Since then, no new discoveries have been made, and the primrose was considered an extinct species. In May 2017 the growth of this species was discovered by us in the Zavodoukovskiy district. This is one of the northernmost locations of $P$. macrocalyx in Western Siberia. A large population has at least a thousand clones on an area of about 4 hectares. Recommendations are given for the inclusion of the $P$. macrocalyx in the list of species to be included in the Red Book of the Tyumen Province.
\end{abstract}

Key words: floristic records; primrose macrocalyx; West Siberia

\section{Primula macrocalyx Bunge (Primulaceae) в Тюменской области}

\author{
О.А. Капитонова, В.И. Капитонов, Ю.А. Тюлькин \\ ФГБУН «Тобольская комплексная научная станция УрО РАН», 626152, \\ Тюменская область, г. Тобольск, ул. им академика Ю. Осипова, 15, Россия \\ e-mail:kapoa.tkns@gmail.com; kvi@udsu.ru;yu.tiulkin@yandex.ru
}

\footnotetext{
Приводятся сведения о находке Primula macrocalyx Bunge в Тюменской области. На территории области данный вид впервые был отмечен П.Н. Крыловым в 1937 г. С тех пор новых находок не было, и первоцвет крупночашечный считался исчезнувшим видом. В мае 2017 г. произрастание этого вида было обнаружено нами в Заводоуковском районе; это одно из самых северных местонахождений P. тасrocalyx в Западной Сибири. Достаточно крупная популяция насчитывает не менее тысячи клонов на площади около 4 га. Даны рекомендации
} 
Kapitonova, O.A. et al. (2017). Primula macrocalyx Bunge.... Acta Biologica Sibirica, 2017, 3(4), 77-80

к включению первоцвета крупночашечного в перечень видов, подлежащих занесению в Красную книгу Тюменской области.

Ключевые слова: флористические находки; первоцвет крупночашечный; Западная Сибирь

\section{Введение}

Первоцвет крупночашечный распространен в Южной Европе, на севере Передней Азии, в Южной Сибири. В Западной Сибири произрастание отмечено в Курганской, Томской, Новосибирской, Кемеровской областях, на юге Алтайского Края (Ковтонюк, 1997). Вид обитает в южной части лесной и в лесостепной зонах, встречаясь по лесным опушкам, разреженным лесам, луговым склонам, пойменным и субальпийским лугам и кустарникам (Крылов, 1937; Ковтонюк, 1997). В равнинном Зауралье местообитания вида в основном приурочены к речным долинам (Науменко, 2008). Впервые на произрастание первоцвета крупночашечного (Primula macrocalyx Bunge) в Тюменской области указал П.Н. Крылов во Флоре Западной Сибири: «в окр. Тюмени у железн. дороги» (Крылов, 1937, с. 2129). Приведенное П.Н. Крыловым местонахождение вида могло свидетельствовать о его заносном характере в регионе. С тех пор новых находок первоцвета крупночашечного не было, и вид считался исчезнувшим с территории области (Перечень..., 2016).

\section{Материал и методы исследования}

В мае 2017 г. в ходе изучения весеннего аспекта биоты в юго-западных районах Тюменской области нами была обнаружена достаточно крупная популяция P. macrocalyx: 1) Тюменская область, Заводоуковский район, в

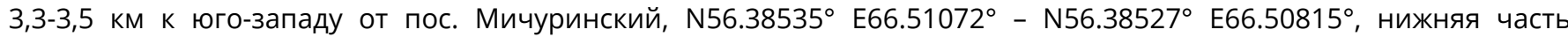
левобережного склона долины безымянного ручья - правого притока р. Березовка, редкостойный березовый лес. 12.V.2017. О.А. Капитонова (О.К.), В.И. Капитонов (В.К.), Ю.А. Тюлькин (Ю.Т.); 2) там же, в 4 км к юго-западу от пос. Мичуринский, N56.38249 E66.49991, нижняя часть правобережного склона долины р. Березовки, осиновоберезовый лес. 12.V.2017. О.К., В.К., Ю.Т.; 3) там же, в 3,3 км к юго-западу от пос. Мичуринский, N56.38803 Е66.50818 ${ }^{\circ}$, нижняя часть правобережного склона безымянного ручья - правого притока р. Березовка, влажная луговина, 12.V.2017. О.К., В.К., Ю.Т. (рис. 1).

Гербарные образцы P. macrocalyx хранятся в Гербарии Тобольской комплексной научной станции УрО РАН.

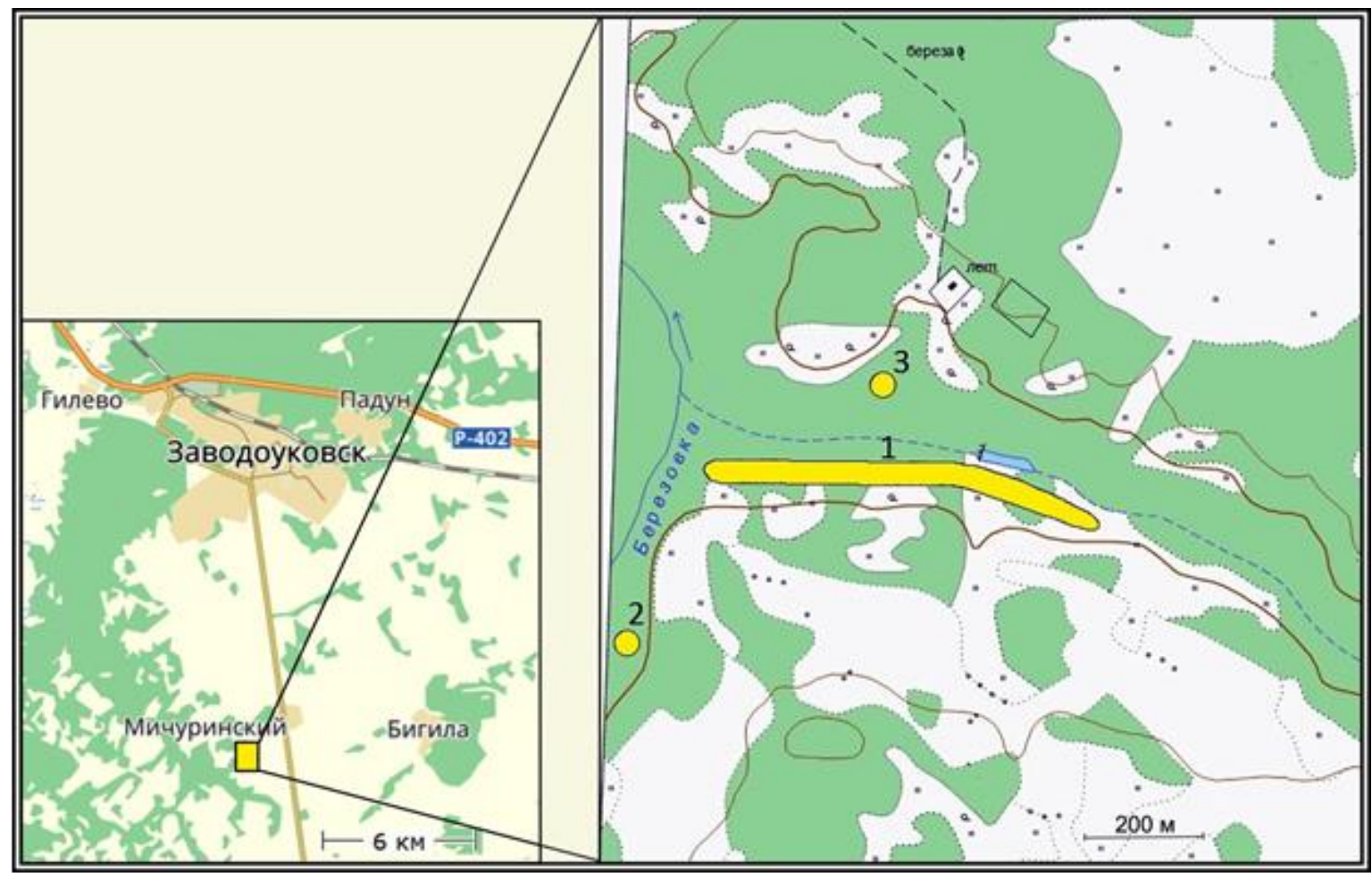

Рис. 1. Карта-схема местонахождения ценопопуляции Primula macrocalyx Bunge в Тюменской области (цифры соответствуют указанным в тексте локалитетам).

\section{Результаты и их обсуждение}

Цитируемое местонахождение является одним из самых северных в сибирском секторе ареала вида; наиболее северная находка вида в регионе известна из Шатровского района Курганской области, близ границы со Свердловской областью (Науменко, 2012). 
Kapitonova, O.A. et al. (2017). Primula macrocalyx Bunge.... Acta Biologica Sibirica, 2017, 3(4), 77-80

В описываемом местонахождении растения произрастали в основном в нижней части склонов северной и западной экспозиции, изредка встречаясь также в кустарниковых зарослях и на влажных луговинах у подножия левобережного склона долины безымянного ручья. Один клон встречен нами на правом берегу ручья (рис. 1). Обследованный нами участок, занимаемый ценопопуляцией первоцвета, имел площадь около 4 га. По самым приблизительным подсчетам популяция насчитывает более 1 тысячи клонов, имеющих до 20 и более генеративных побегов (рис. 2). Время проведения исследований совпало с периодом начала массового цветения первоцвета, который составлял негустой желто-зеленый весенний аспект на склонах долины ручья. Кроме него в составе сообществ зафиксировано еще более десятка видов сосудистых растений, большей частью находившихся в момент проведения описания в состоянии вегетации или бутонизации, реже - начала цветения (табл. 1).

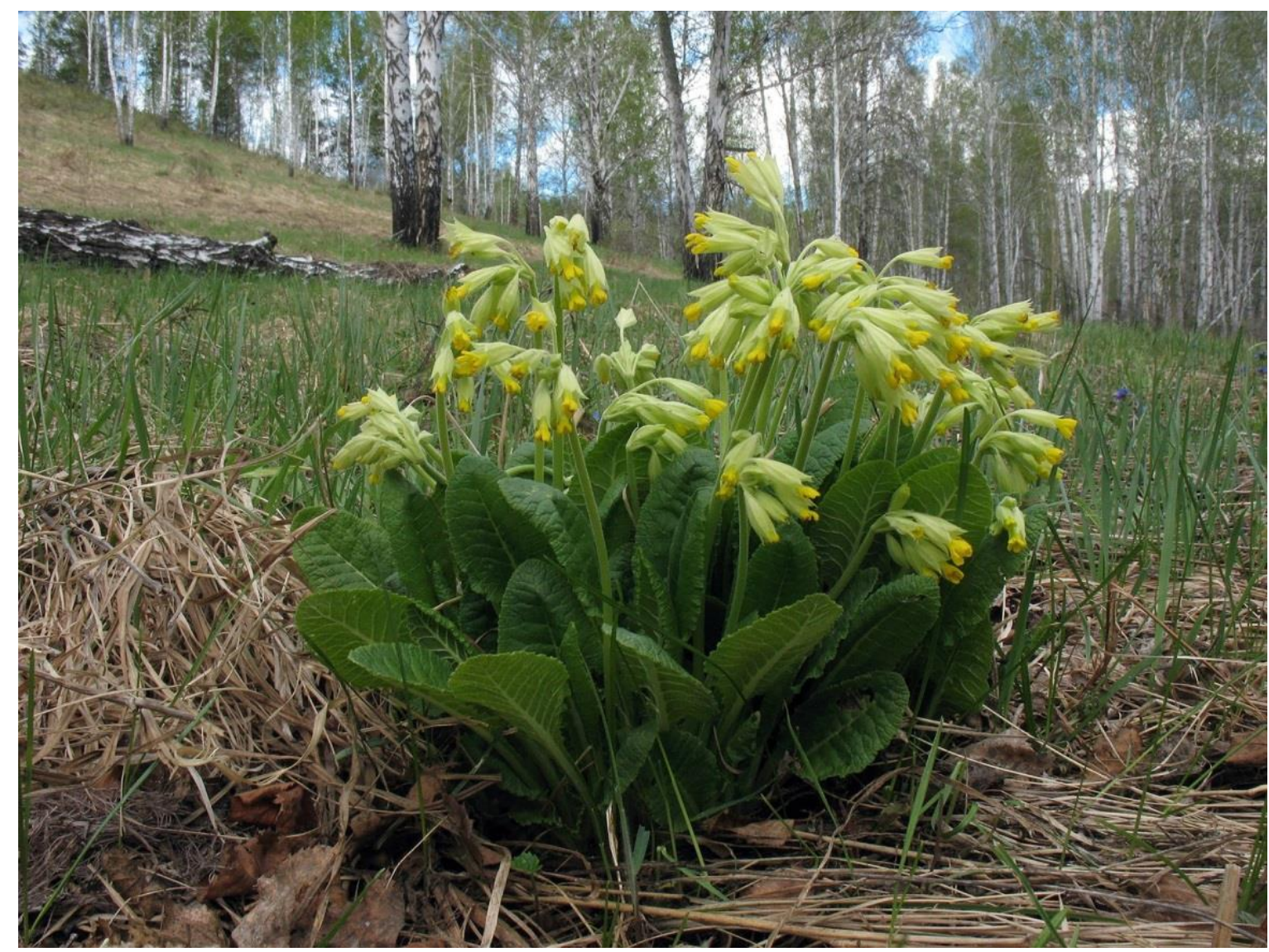

Pис 2. Primula macrocalyx Bunge: общий вид клона из описываемого местонахождения

(Фото В.И. Капитонова, 12.V.2017)

Таблица 1. Состав сообщества с Primula macrocalyx Bunge в Тюменской области

\begin{tabular}{|c|c|c|}
\hline Дата описания & \multicolumn{2}{|c|}{ 12.V.2017 } \\
\hline Местонахождение & \multicolumn{2}{|c|}{$\begin{array}{l}\text { Тюменская область, Заводоуковский район, в 3,3 км к юго-западу от } \\
\text { пос. Мичуринский }\end{array}$} \\
\hline Биотоп & \multicolumn{2}{|c|}{ Нижняя часть склона долины ручья } \\
\hline Ассоциация & \multicolumn{2}{|c|}{ Березняк редкостойный вейниково-разнотравный } \\
\hline Автор описания & \multicolumn{2}{|c|}{ О.А. Капитонова } \\
\hline Площадь описания, м² & \multicolumn{2}{|l|}{100} \\
\hline 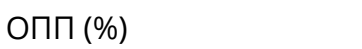 & \multirow{2}{*}{\multicolumn{2}{|c|}{$\begin{array}{l}90 \\
\text { север }\end{array}$}} \\
\hline Экспозиция & & \\
\hline Число видов & \multicolumn{2}{|l|}{14} \\
\hline Вид & $\begin{array}{l}\text { Обилие по шкале Браун- } \\
\text { Бланке }\end{array}$ & $\begin{array}{l}\text { Фенологическое } \\
\text { состояние }\end{array}$ \\
\hline Betula pendula & 2 & вег. \\
\hline Populus tremula & + & вег.-отцвет. \\
\hline Padus avium & + & вег.-бут. \\
\hline
\end{tabular}


Kapitonova, O.A. et al. (2017). Primula macrocalyx Bunge.... Acta Biologica Sibirica, 2017, 3(4), 77-80

$\begin{array}{lll}\text { Rosa majalis } & + & \text { вег. } \\ \text { Salix cinerea } & + & \text { вег.-цв. } \\ \text { Calamagrostis epigeios } & 4 & \text { вег. } \\ \text { Filipendula ulmaria } & 1 & \text { вег. } \\ \text { Primula macrocalyx } & 1 & \text { цв. } \\ \text { Serratula coronata } & + & \text { вег. } \\ \text { Pulmonaria mollis } & + & \text { цв. } \\ \text { Trollius europaeus } & + & \text { бут. } \\ \text { Lathyrus vernus } & + & \text { вег.-бут. } \\ \text { Angelica sylvestris } & + & \text { вег. } \\ \text { Glechoma hederacea } & + & \text { вег.-бут. }\end{array}$

Склоны ручья, на которых обнаружена популяция $P$. macrocalyx, подвергаются умеренному антропогенному воздействию, которое выражается в основном в нерегулярном выпасе крупного рогатого скота, из-за чего один из участков некогда залесенного склона превращен в пастбищный луг. В этом месте ручей перегорожен дамбой, по которой проложена грунтовая дорога, поднимающаяся далее по склону долины. При строительстве дамбы и дороги часть популяции первоцвета была уничтожена. Усиление антропогенной нагрузки на указанные биотопы приведет к увеличению риска сокращения численности и плотности популяции Р. macrocalyx, в особенности ее восточной части.

Первоцвет крупночашечный внесен в ряд региональных Красных книг европейской части России и Сибири, в том числе в Красные книги Курганской (Науменко, 2012) и Томской (Амельченко и др., 2013) областей. В связи с тем, что на территории Тюменской области на данный момент достоверно известно всего лишь одно местонахождение $P$. macrocalyx, которое подвергается антропогенному воздействию, рекомендуем включить этот вид в перечень видов живых организмов, подлежащих занесению в готовящееся в настоящее время второе издание Красной книги Тюменской области с категорией редкости 1 - вид, находящийся на грани исчезновения.

\section{Благодарности}

Работа выполнена в рамках темы ФНИ «Современное состояние биологического разнообразия юга Западной Сибири как отражение антропогенной трансформации ландшафтов» (№ ГР 116020510081).

\section{References}

Amelchenko, V.P., Zaykova, E.V., and Kataeva, T.N. (2013). Primrose macrocalyx. In The Red Data Book of the Tomsk Province. Tomsk: Publishing house "Printing Manufactory". (In Russian)

Kovtonyuk, N.K. (1997). The Family Primulaceae. In Flora of Siberia, vol. 11: Pyrolaceae - Lamiaceae (Labiatae) (pp. 30 47). Novosibirsk, Nauka, Siberian Publishing Company RAS. (In Russian)

Krylov, P. (1937). Flora of the West Siberia. Guide to the definition of West Siberian plants. Issue IX. Pyrolaceae - Labiatae. Tomsk. (In Russian)

List of species of animals, plants and fungi to be included in the Red Data Book of the Tyumen Province: Appendix to the Resolution of the Government of the Tyumen Province dated April 18, 2016 No. 155-p. (In Russian)

Naumenko, N.I. (2008). On the Flora and Vegetative Cover of Southern Zauralye. Kurgan, Kurgan University Press. (In Russian)

Naumenko, N.I. (2012). Primrose macrocalyx. In The Red Data Book of the Kurgan Province (p. 337). Kurgan, Kurgan University Press. (In Russian)

\section{Citation:}

Kapitonova, O.A., Kapitonov, V.I., Tyulkin, Yu.A. (2017). Primula macrocalyx Bunge (Primulaceae) in the Tyumen Province. Acta Biologica Sibirica, 3 (4), 77-80.

Submitted: 15.07.2016. Accepted: 14.09.2017

crossref http://dx.doi.org/10.14258/abs.v3i4.3632

(C) 2017 by the authors. Submitted for possible open access publication under the terms and conditions of the Creative Commons Attribution (CC BY) license (http://creativecommons.org/licenses/by/4.0/). 